\title{
Contralateral anterior interhemispheric- transcallosal-transrostral approach to the subcallosal region: a novel surgical technique
}

\author{
Feres Chaddad-Neto, MD, PhD, ${ }^{1}$ Marcos Devanir Silva da Costa, MD, MSc, ${ }^{1}$ Baran Bozkurt, MD, ${ }^{2}$ \\ Hugo Leonardo Doria-Netto, MD, ${ }^{1}$ Daniel de Araujo Paz, MD, ${ }^{1}$ Ricardo da Silva Centeno, MD, PhD, ${ }^{1}$ \\ Andrew W. Grande, MD, ${ }^{2}$ Sergio Cavalheiro, MD, PhD, ${ }^{1}$ Kaan Yağmurlu, MD, ${ }^{3}$ \\ Robert F. Spetzler, MD, ${ }^{3}$ and Mark C. Preul, MD ${ }^{3}$
}

\begin{abstract}
1Department of Neurosurgery, Federal University of São Paulo, São Paulo, Brazil; '2Department of Neurosurgery, University of Minnesota, Minneapolis, Minnesota; and ' ${ }^{3}$ Department of Neurosurgery, Barrow Neurological Institute, St. Joseph's Hospital and Medical Center, Phoenix, Arizona
\end{abstract}

OBJECTIVE The authors report a novel surgical route from a superior anatomical aspect-the contralateral anterior interhemispheric-transcallosal-transrostral approach-to a lesion located in the subcallosal region. The neurosurgical approach to the subcallosal region is challenging due to its deep location and close relationship with important vascular structures. Anterior and inferior routes to the subcallosal region have been described but risk damaging the branches of the anterior cerebral artery.

METHODS Three formalin-fixed and silicone-injected adult cadaveric heads were studied to demonstrate the relationships between the transventricular surgical approach and the subcallosal region. The surgical, clinical, and radiological history of a 39-year-old man with a subcallosal cavernous malformation was retrospectively used to document the neurological examination and radiographic parameters of such a case.

RESULTS The contralateral anterior interhemispheric-transcallosal-transrostral approach provides access to the subcallosal area that also includes the inferior portion of the pericallosal cistern, lamina terminalis cistern, the paraterminal and paraolfactory gyri, and the anterior surface of the optic chiasm. The approach avoids the neurocritical perforating branches of the anterior communicating artery.

CONCLUSIONS The contralateral anterior interhemispheric-transcallosal-transrostral approach may be an alternative route to subcallosal area lesions, with less risk to the branches of the anterior cerebral artery, particularly the anterior communicating artery perforators.

https://thejns.org/doi/abs/10.3171/2017.4.JNS16951

KEY WORDS anatomy; cavernous malformation; corpus callosum; interhemispheric transcallosal; subcallosal region; surgical approach; surgical technique

$\mathrm{T}$ He subcallosal area is the inferomedial portion of the frontal lobe located rostral to the corpus callosum. Reaching the subcallosal region has been a challenge for neurosurgeons because of its deep location and close relationship with important vascular structures. Inferior routes, such as the fronto-orbitozygomatic transsylvian approach, or anterior routes, such as the infrafrontal interhemispheric approach, have been most commonly used to approach lesions in the subcallosal area. . $^{2-5,8-10,12,14 \text {, }}$ ${ }^{15,20}$ The hazard of anterior and inferior routes to the subcallosal region is possible damage to the branches of the anterior cerebral artery (ACA), particularly the hypothalamic and subcallosal branches. Injury to these arterial branches may result in memory impairment, amnestic-confabulatory syndrome, or hypothalamic problems. Additionally, a transventricular preforniceal approach, which is a route

ABBREVIATIONS ACA = anterior cerebral artery; $\mathrm{ACOA}=$ anterior communicating artery.

SUBMITTED April 13, 2016. ACCEPTED April 4, 2017.

INCLUDE WHEN CITING Published online November 3, 2017; DOI: 10.3171/2017.4.JNS16951. 

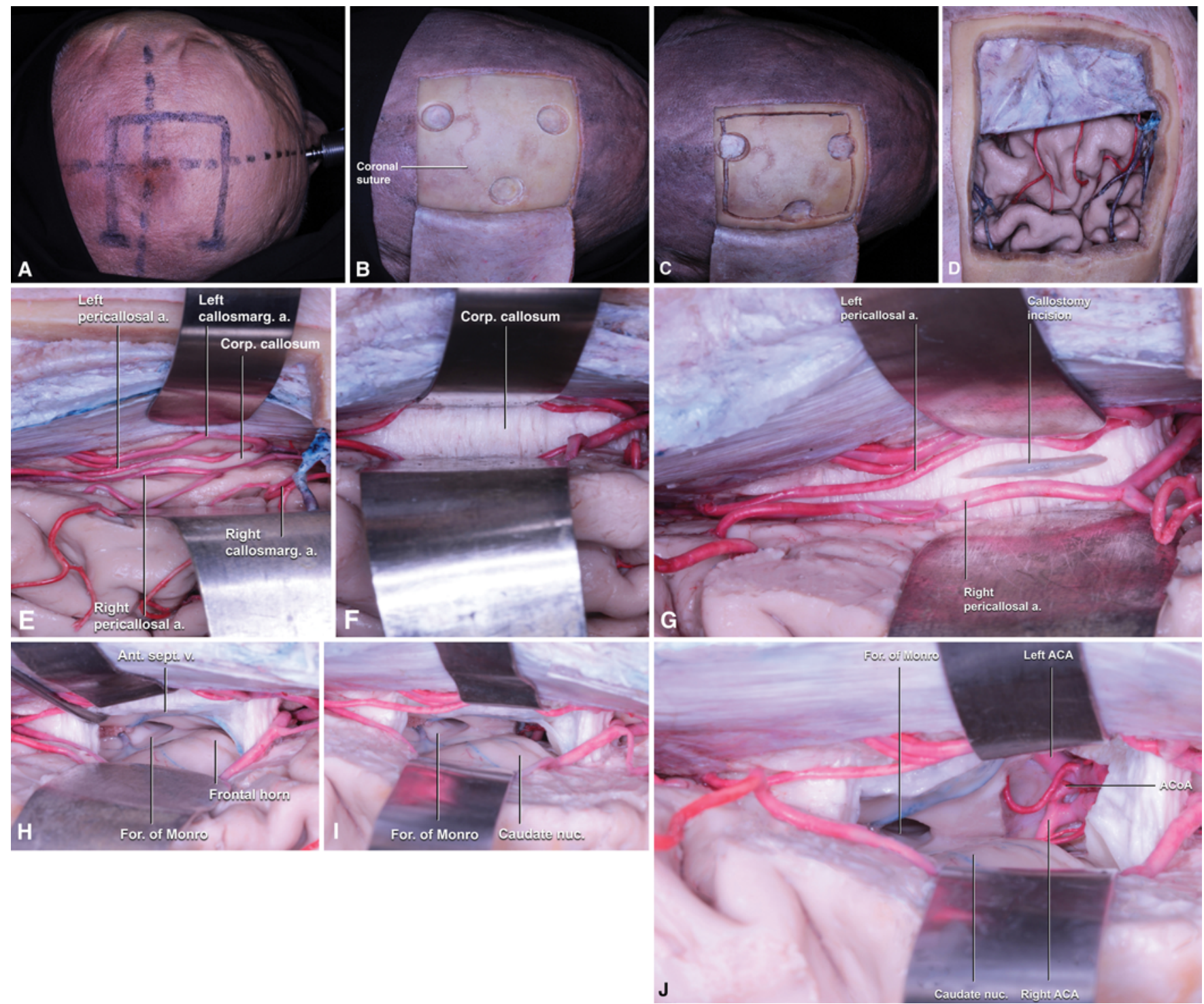

FIG. 1. A: With the patient in the supine position, the head is turned so that the nonlesion side (right side) is placed down, and the lesion side (left side) is placed up to target the subgenual area. A horseshoe-shaped skin incision is performed. One-third of the skin incision is made on the upper side of the head and two-thirds on the lower side. B: After reflecting the skin flap toward the floor, 2 bur holes are opened over the superior sagittal sinus, and 1 bur hole is opened laterally. C: The craniotomy flap is turned by crossing the midline. D: The dura is cut and reflected over the sinus. E: After proceeding into the interhemispheric fissure, the distal branches of the ACA and corpus callosum are observed. F: The distal branches of the ACA are retracted to either side to expose the corpus callosum. G: The corpus callosum is incised in a vertical direction. H: After the callosal incision, the right lateral ventricle (nonlesion side) is entered, and the foramen of Monro is identified. I and J: Moving forward, the floor of the frontal horn of the lateral ventricle is exposed, and a vertical incision is made starting $15 \mathrm{~mm}$ anterior to the foramen of Monro to reach the subgenual area. This incision corresponds to the rostrum of the corpus callosum. The branches of the ACA and contralateral subgenual area are exposed. a $_{\text {. }}$ artery; Ant. sept. v. = anterior septal vein; callosomarg. = callosomarginal; Corp. = corpus; For. = foramen; nuc. $=$ nucleus. Dissections prepared by Baran Bozkurt, MD, at the University of Minnesota. Used with permission from the University of Minnesota, Minneapolis, Minnesota.

from the superior aspect, has been described as a way to reach the chiasmatic or hypothalamic regions situated behind the subcallosal region. ${ }^{19}$ We describe a novel surgical route from the superior anatomical aspect-a contralateral anterior interhemispheric-transcallosal-transrostral approach for reaching the subcallosal area. We also report an illustrative case of a patient with a subcallosal cavern- ous malformation and an anteriorly located developmental venous anomaly.

\section{Methods}

Three formalin-fixed and artery/vein silicone-injected adult cadaveric heads were studied under $6 x$ and $40 x$ 

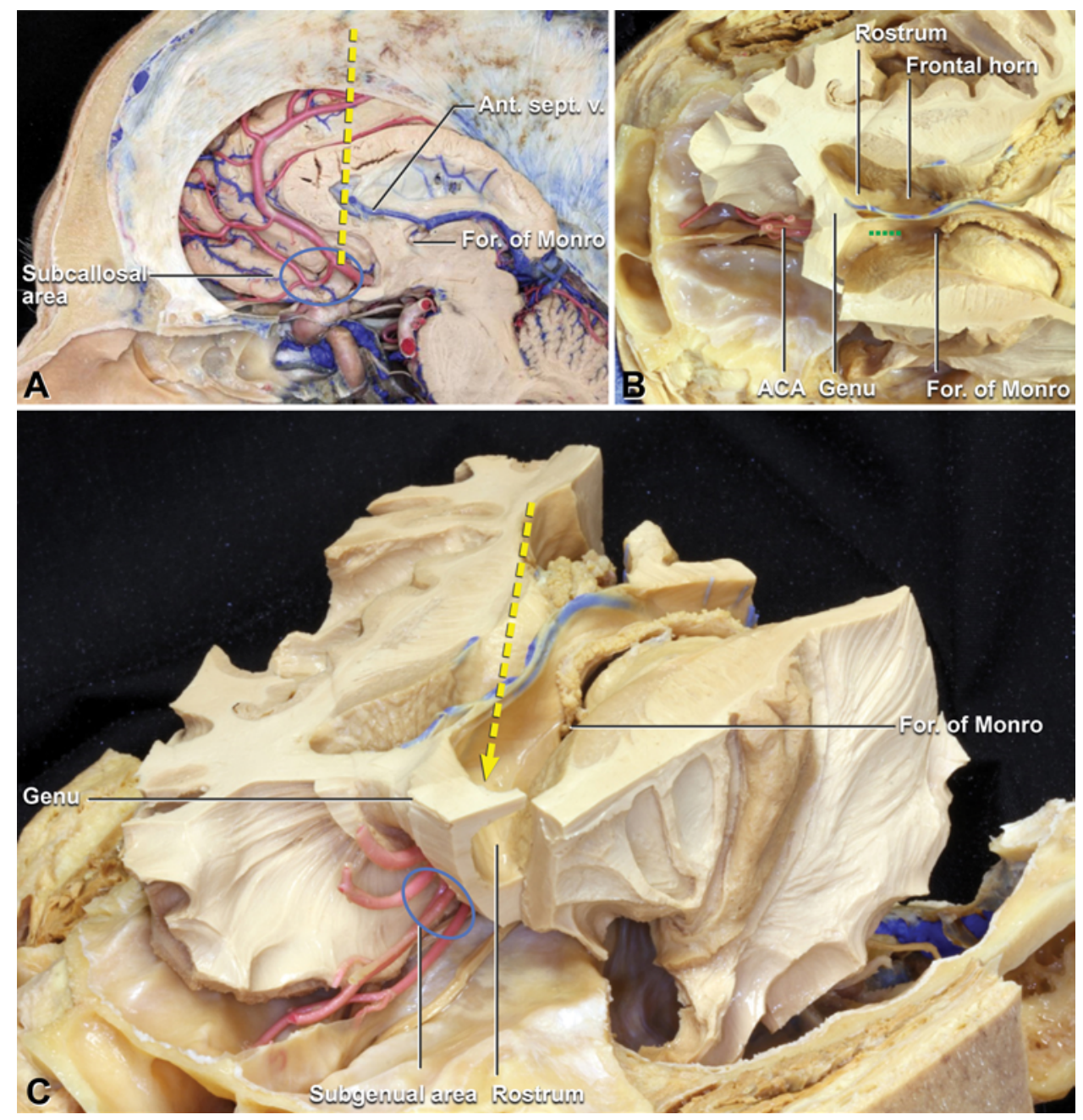

FIG. 2. Anatomical dissection. A: Medial view shows the trajectory (yellow dashed line) of the anterior interhemispherictranscallosal-transrostral approach to the septal region (blue circle). B: Superior view of the lateral ventricle shows the rostrum of the corpus callosum, which forms the floor of the frontal horn of the lateral ventricle. A paramedian rostral incision (green dashed line) is made $15 \mathrm{~mm}$ anterior to the foramen of Monro. C: Oblique view shows the relationship of the rostrum of the corpus callosum, the septal region, and the ACA. The yellow dashed arrow shows the superior route to the rostrum of the corpus callosum through the left lateral ventricle to reach the right subgenual region. Dissections prepared by Kaan Yağmurlu, MD. Reproduced with permission from the Rhoton Collection (http://rhoton.ineurodb.org), CC BY-NC-SA 4.0 (http://creativecommons.org/licenses/ by-nc-sa/4.0).

magnification using a Zeiss Surgical Microscope (Carl Zeiss $\mathrm{AG}$ ) to assess the relationships between the transventricular route and the subcallosal region. The clinical, radiological, and surgical history of a 39-year-old man with a subcallosal cavernous malformation was reviewed retrospectively to document the neurological examination and radiographic parameters of such a case.

\section{Results}

\section{Surgical Technique}

For a contralateral anterior interhemispheric-transcallosal-transrostral approach, the patient is placed in the supine position with the head elevated $45^{\circ}$ above the heart level. After head fixation, the sagittal plane is aligned parallel to the floor, allowing the surgeon's hands to work naturally from side to side (Fig. 1). The side of the lesion being surgically treated is placed superiorly for an optimal view of the approach, with the nonlesion side placed downward. ${ }^{21}$

A linear skin incision is made precoronally and perpendicular to the midline, with one-third of the incision on the lesion side (ipsilateral side) and the other two-thirds on the nonlesion side (contralateral side). Then, 2 bur holes are placed over the superior sagittal sinus, and another bur hole is placed approximately $3-4 \mathrm{~cm}$ lateral to the midline. After removing the bone, the dura mater is opened in a $U$ shape and retracted with tension sutures over the sinus. The interhemispheric fissure is easily opened and accessed in a trajectory from the coronal suture level to the anterior one-third of the body of the corpus callosum to reach the foramen of Monro, which is located at the 

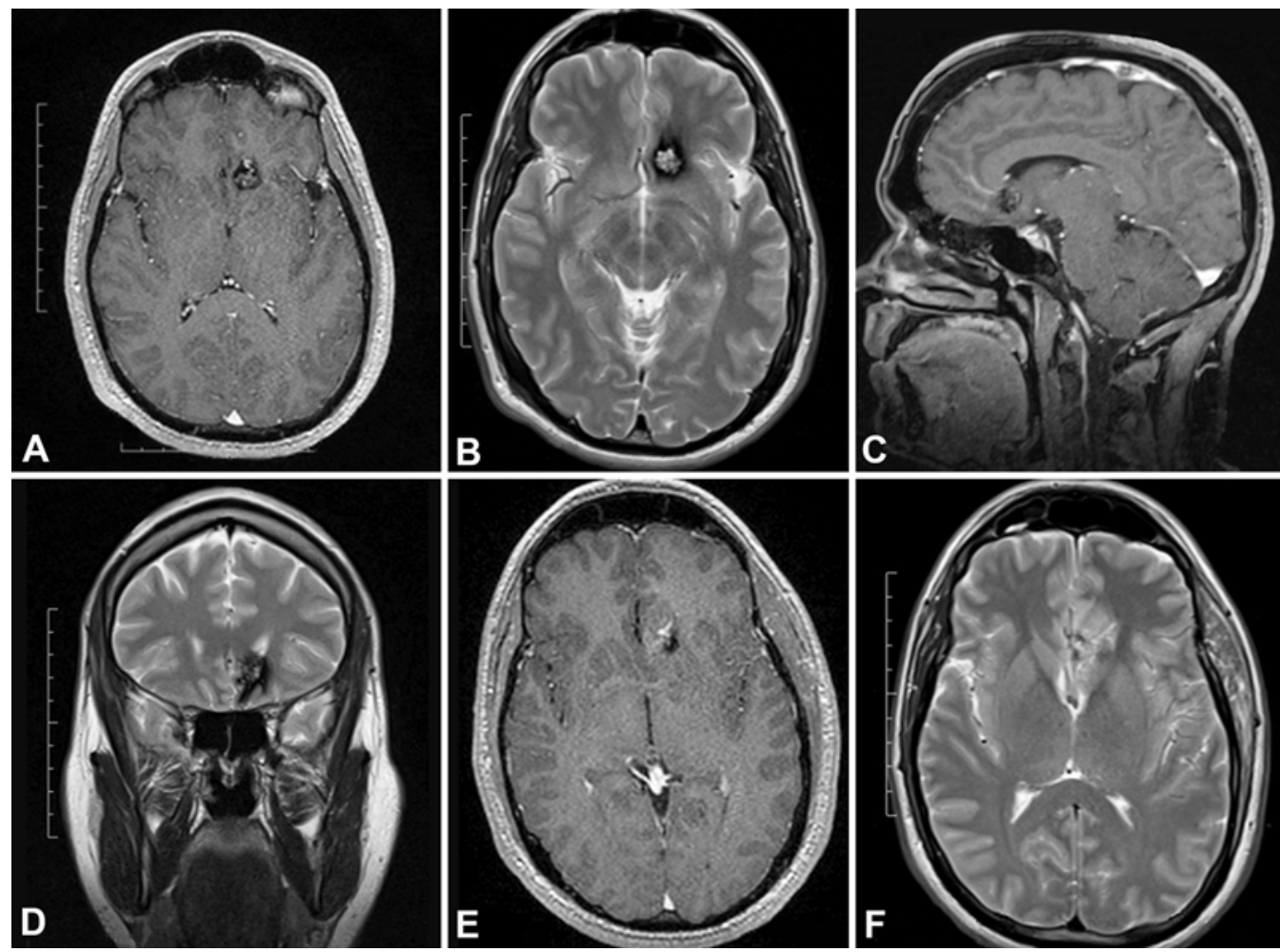

FIG. 3. Preoperative and postoperative MR images obtained in a 39-year-old man with partial complex seizures who was diagnosed with a subcallosal cavernous malformation. Preoperative axial T1-weighted MR image with contrast enhancement $(\mathbf{A})$ and axial T2-weighted MR image (B) show a mixed lesion with a hypointense hemosiderin halo revealing a "popcorn-like" area in the left subcallosal region. Sagittal T1-weighted MR image (C) shows a popcorn-like lesion below the rostrum of the corpus callosum, with minimal gadolinium enhancement. Coronal T2-weighted MR image (D). Postoperative axial T1-weighted MR image (E) shows no gadolinium enhancement. Postoperative axial T2-weighted MR image (F) shows gross-total resection of the lesion. Provided by the Federal University of São Paulo, Brazil.

same coronal level as the junction of the coronal suture and sagittal sinus in the midline.

With this technique, at a deeper location, both cingulate gyri may be adjacent to each other because the falx cerebri does not touch the surface of the anterior one-third of the body of the corpus callosum. The cingulate gyri may hide the corpus callosum and pericallosal arteries, making dissection in this area more difficult. The pericallosal arteries are meticulously dissected and retracted laterally, and the corpus callosum is incised longitudinally $1.5-2$ $\mathrm{cm}$ by starting at the point corresponding to the same coronal level as the coronal suture and proceeding forward to enter the lateral ventricle, which has been positioned downward (nonlesion side). After exposure of the foramen of Monro, the surgeon progresses forward to observe the rostrum of the corpus callosum, which forms the floor of the frontal horn of the lateral ventricle. A paramedian incision to the rostrum of the corpus callosum is made longitudinally by starting $1.5 \mathrm{~cm}$ anterior to the foramen of Monro and the column of the fornix to avoid damage to both the fornix and the anterior commissure. The opening of the rostrum of the corpus callosum exposes the contralateral subcallosal region on the lesion side, the ACA, and the anterior communicating artery (ACoA) and its branches (Fig. 2).

\section{Illustrative Case}

A 39-year-old man with partial complex seizures was diagnosed with a cavernous malformation and an associated anteriorly located developmental venous anomaly in the left subcallosal area (Fig. 3). The patient underwent a contralateral (right side) anterior interhemispheric-transcallosal-transrostral approach to the lesion. When the rostrum of the corpus callosum was opened on the right side, a yellowish lesion was identified in the contralateral subcallosal area (left side). The lesion was removed along with the adjacent hemosiderin-stained tissue, while preserving the venous anomaly (Fig. 4). Following an uneventful postoperative course, MRI studies showed grosstotal resection of the lesion, and the patient's antiepileptic drugs were discontinued 2 months later.

\section{Discussion}

The advantage of the contralateral anterior interhemispheric-transcallosal-transrostral approach over the others described in the medical literature is that it provides improved situational access to the subcallosal area. This area also includes the inferior portion of the pericallosal cistern, the lamina terminalis cistern, the paraterminal and paraolfactory gyri, and the anterior surface of the op- 

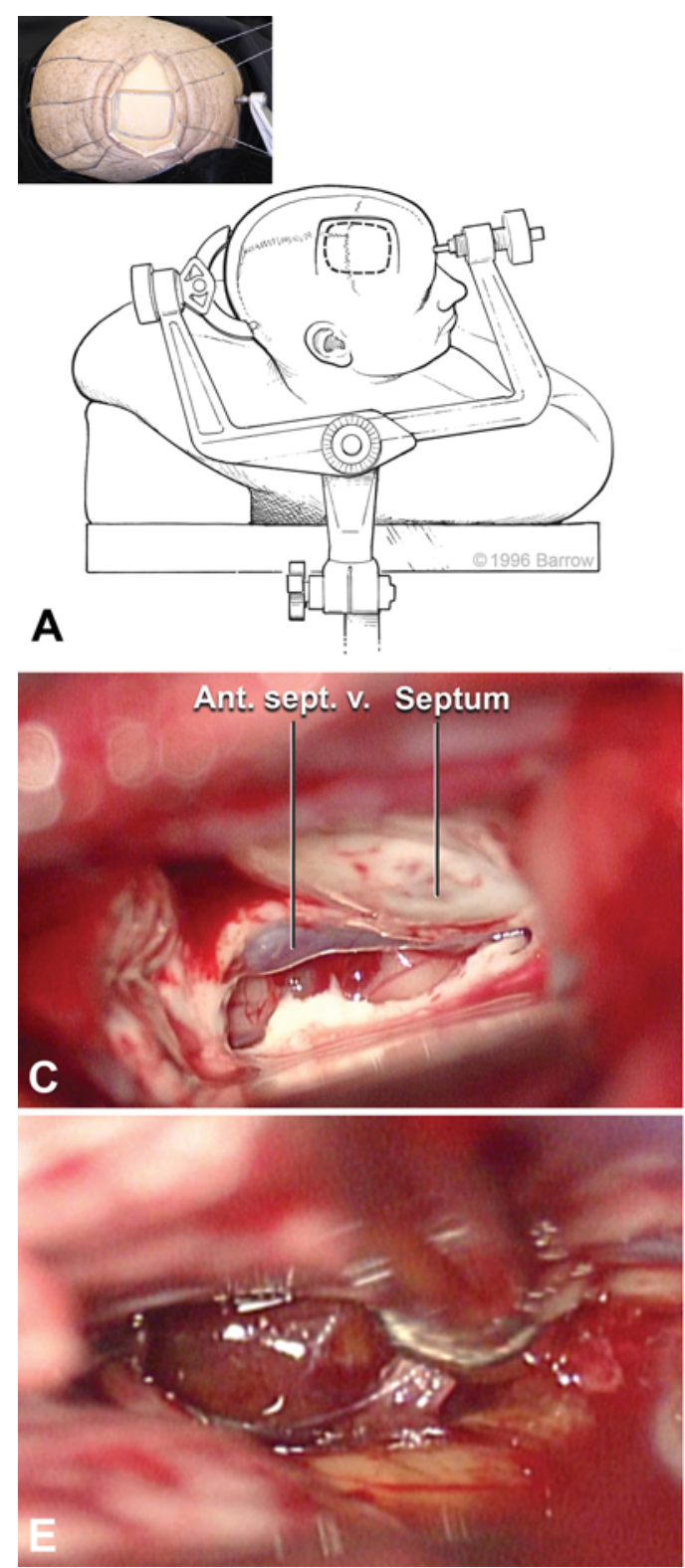
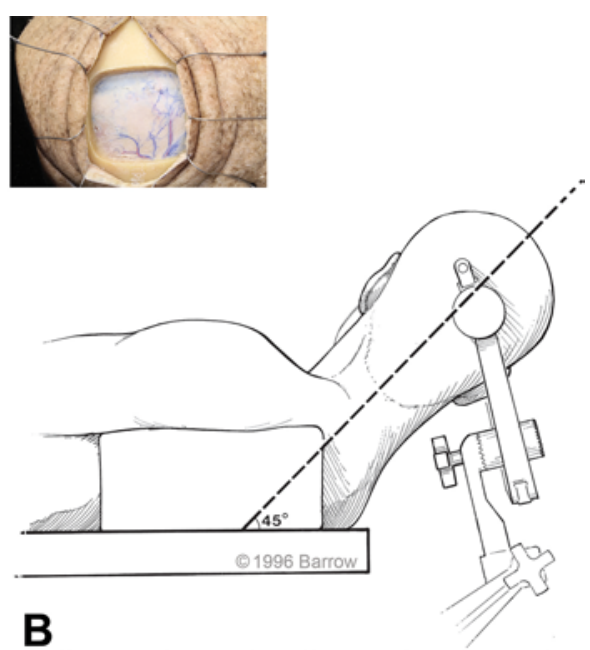

B
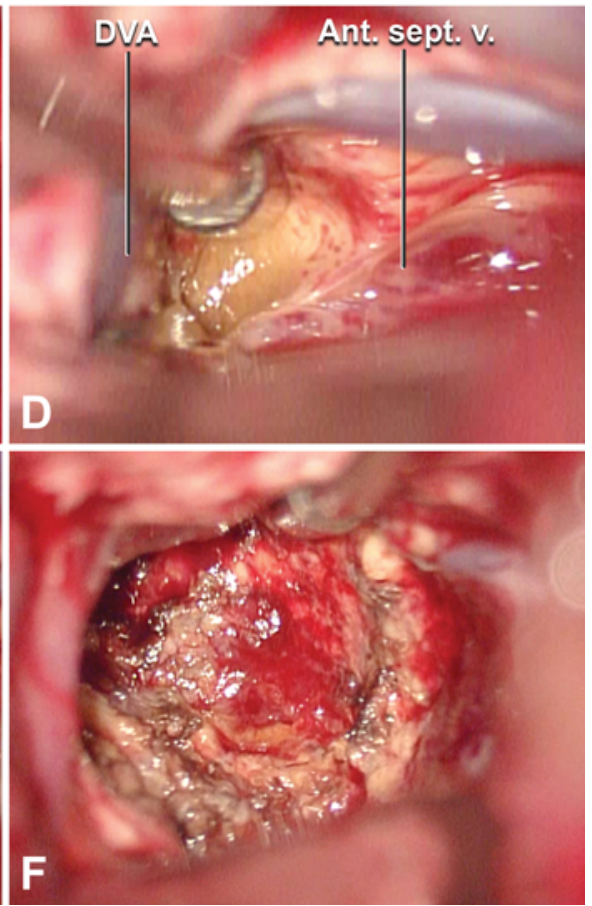

FIG. 4. Patient positioning and intraoperative pictures. A and B: Patient and head positions for the contralateral anterior interhemispheric-transcallosal-transrostral approach. C and D: The rostral incision in the right-sided callosotomy exposes the anteriorly located deep venous anomaly (DVA) and a yellowish cavernous malformation in the left subcallosal region. E and F: Surgical view after removal of the cavernous malformation and surrounding gliotic area. Insets portray dissections prepared by Kaan Yağmurlu, MD. Reproduced with permission from the Rhoton Collection (http://rhoton.ineurodb.org), CC BY-NC-SA 4.0 (http://creativecommons.org/licenses/by-nc-sa/4.0). Panels A and B are used with permission from Barrow Neurological Institute, Phoenix, Arizona. Panels C-F are used with permission from the Federal University of São Paulo, Brazil.

tic chiasm, without encountering the critical perforating branches of the ACoA.

The contralateral anterior interhemispheric-transcallosal-transrostral approach provides direct and better lateral exposure to the contralateral hemisphere (lesion side) than the exposure provided by an ipsilateral approach, even with minimal hemisphere retraction. ${ }^{21}$ After opening the interhemispheric fissure, the lesion is pulled by gravity in the opposite direction to provide a better view for the surgeon, with less of a requirement for retraction of the nonlesion hemisphere with the assistance of gravity. The trajectory from above, through the lateral ventricle, provides exposure to the bilateral ACA in the subgenual region. The removal of the lesion via the contralateral route is easier and safer than its removal via an ipsilateral route because of greater lateral exposure., ${ }^{7,21}$

The subcallosal area is bordered superiorly by the rostrum and genu of the corpus callosum, posteroinferiorly by the lamina terminalis, and posteriorly by the paraterminal and paraolfactory gyri. ${ }^{13}$ The most common approaches 
to the subcallosal area are a fronto-orbitozygomatic craniotomy with a transsylvian supracarotid-infrafrontal route $^{4,12,16}$ and an anterior frontal craniotomy with an anterior subfrontal interhemispheric approach. ${ }^{5}$ Waldron and Lawton ${ }^{16}$ noted a supracarotid-infrafrontal route to cavernous malformations in the anteroinferior part of the basal ganglia in 5 patients, 2 of whom had transient neurological deficits. Rangel-Castilla and Spetzler ${ }^{12}$ also used an orbitozygomatic supracarotid-infrafrontal approach for removal of cavernous malformations located in the anteroinferior region of the thalamus. They reported that $20 \%$ of patients had postoperative transient hemiparesis related to a small internal capsule stroke. In the subcallosal area, this complication may be related to cisternal lesions because superiorly or posteriorly directed ACoA aneurysms are commonly treated via a fronto-orbitozygomatic approach. With a transsylvian, subfrontal, anterior interhemispheric dissection of the lamina terminalis and the inferior pericallosal cisterns, this complication may be related to accidental injury of the subcallosal artery, causing memory impairment and amnestic-confabulatory syndrome.

The transventricular preforniceal approach described by Yoshimoto et al. ${ }^{19}$ has been used to remove exophytic chiasmatic-hypothalamic astrocytomas extending into the anterior third of the lateral ventricle by entering through the bulk of the tumor. In our case, the presence of a cavernous malformation with an anteriorly located venous anomaly draining into the anterior septal vein prompted a surgical approach from above the lesion, rather than from an anterior or inferior route. Such an approach also helps to avoid manipulation of the critical perforating arteries. In our contralateral anterior interhemispheric-transcallosal-transrostral approach, the dissection into the rostrum of the corpus callosum must be made $15 \mathrm{~mm}$ away from the anterior limit of the column of the fornix. At this point, a safe entry zone exists that avoids damage to the anterior commissure, which has a mean distance from the foramen of Monro of $3.3 \mathrm{~mm}$ (range 1.9-5.4 mm), as described in anatomical studies, and $6.7 \mathrm{~mm}$ (range $1.8-14.5 \mathrm{~mm}$ ), as described in radiological studies. ${ }^{6,17,18}$

Although our patient had no postoperative neurological or neuropsychological deficit, the transcallosal approach has been associated with adverse functional outcomes for memory and executive functions, and with learning impairment. ${ }^{1,11}$ However, most of these studies included patients who underwent resections of lesions via the transcallosal approach with manipulation of the fornix.

\section{Conclusions}

The contralateral anterior interhemispheric-transcallosal-transrostral approach may be an alternative route to lesions in the subcallosal area, with less risk to the branches of the ACA, particularly the ACoA perforators.

\section{Acknowledgments}

This study was supported in part by funds from the Newsome Chair in Neurosurgery Research held by Dr. Preul, the Barrow Women's Board, and the Barrow Neurological Foundation. We thank the Neuroscience Publications staff at Barrow Neurological Institute for assistance with manuscript preparation.

\section{References}

1. Apuzzo ML, Chikovani OK, Gott PS, Teng EL, Zee CS, Giannotta SL, et al: Transcallosal, interfornicial approaches for lesions affecting the third ventricle: surgical considerations and consequences. Neurosurgery 10:547554,1982

2. Campero A, Martins C, Socolovsky M, Torino R, Yasuda A, Domitrovic L, et al: Three-piece orbitozygomatic approach. Neurosurgery 66 (3 Suppl Operative):E119-E120, 2010

3. Chaddad-Neto F, Campos Filho JM, Dória-Netto HL, Faria MH, Ribas GC, Oliveira E: The pterional craniotomy: tips and tricks. Arq Neuropsiquiatr 70:727-732, 2012

4. Chang EF, Gabriel RA, Potts MB, Berger MS, Lawton MT: Supratentorial cavernous malformations in eloquent and deep locations: surgical approaches and outcomes. Clinical article. J Neurosurg 114:814-827, 2011

5. Ehni G: Interhemispheric and percallosal (transcallosal) approach to the cingulate gyri, intraventricular shunt tubes, and certain deeply placed brain lesions. Neurosurgery 14:99110,1984

6. Erturk M, Kayalioglu G, Ozer MA, Ozgur T: Morphometry of the anterior third ventricle region as a guide for the transcallosal-interforniceal approach. Neurol Med Chir (Tokyo) 44:288-293, 2004

7. Lawton MT, Golfinos JG, Spetzler RF: The contralateral transcallosal approach: experience with 32 patients. Neurosurgery 39:729-735, 1996

8. Marinković S, Milisavljević M, Marinković Z: Branches of the anterior communicating artery. Microsurgical anatomy. Acta Neurochir (Wien) 106:78-85, 1990

9. Meila D, Saliou G, Krings T: Subcallosal artery stroke: infarction of the fornix and the genu of the corpus callosum. The importance of the anterior communicating artery complex. Case series and review of the literature. Neuroradiology 57:41-47, 2015

10. Mugikura S, Kikuchi H, Fujii T, Murata T, Takase K, Mori E, et al: MR imaging of subcallosal artery infarct causing amnesia after surgery for anterior communicating artery aneurysm. AJNR Am J Neuroradiol 35:2293-2301, 2014

11. Peltier J, Roussel M, Gerard Y, Lassonde M, Deramond H, Le Gars D, et al: Functional consequences of a section of the anterior part of the body of the corpus callosum: evidence from an interhemispheric transcallosal approach. J Neurol 259:1860-1867, 2012 (Erratum in J Neurol 26:1199, 2013)

12. Rangel-Castilla L, Spetzler RF: The 6 thalamic regions: surgical approaches to thalamic cavernous malformations, operative results, and clinical outcomes. J Neurosurg 123:676-685, 2015

13. Rhoton AL Jr: The cerebrum. Neurosurgery 51 (4 Suppl):S1-S51, 2002

14. Santoro A, Salvati M, Vangelista T, Delfini R, Cantore GP: Fronto-temporo-orbito-zygomatic approach and variants. Surgical technique and indications. J Neurosurg Sci 47:141147, 2003

15. Shirane R, Ching-Chan S, Kusaka Y, Jokura H, Yoshimoto $\mathrm{T}$ : Surgical outcomes in 31 patients with craniopharyngiomas extending outside the suprasellar cistern: an evaluation of the frontobasal interhemispheric approach. J Neurosurg 96:704-712, 2002

16. Waldron JS, Lawton MT: The supracarotid-infrafrontal approach: surgical technique and clinical application to cavernous malformations in the anteroinferior basal ganglia. Neurosurgery 64 (3 Suppl):ons86-ons95, 2009

17. Winkler PA, Weis S, Büttner A, Raabe A, Amiridze N, Reulen HJ: The transcallosal interforniceal approach to the third ventricle: anatomic and microsurgical aspects. Neurosurgery 40:973-982, 1997

18. Winkler PA, Weis S, Wenger E, Herzog C, Dahl A, Reulen HJ: Transcallosal approach to the third ventricle: normative 
morphometric data based on magnetic resonance imaging scans, with special reference to the fornix and forniceal insertion. Neurosurgery 45:309-319, 1999

19. Yoshimoto K, Shono T, Matsukado K, Sasaki T: The transventricular preforniceal approach for exophytic chiasmatic/hypothalamic astrocytomas extending into the anterior third ventricle. Acta Neurochir (Wien) 155:727732,2013

20. Zabramski JM, Kiriş T, Sankhla SK, Cabiol J, Spetzler RF: Orbitozygomatic craniotomy. Technical note. J Neurosurg 89:336-341, 1998

21. Zaidi HA, Chowdhry SA, Nakaji P, Abla AA, Spetzler RF: Contralateral interhemispheric approach to deep-seated cavernous malformations: surgical considerations and clinical outcomes in 31 consecutive cases. Neurosurgery 75:80-86, 2014

\section{Disclosures}

The authors report no conflict of interest concerning the materi- als or methods used in this study or the findings specified in this paper.

\section{Author Contributions}

Conception and design: Preul, Chaddad-Neto, Devanir Silva da Costa, Yağmurlu. Acquisition of data: Chaddad-Neto, Devanir Silva da Costa, Leonardo Doria-Netto, de Araujo Paz, da Silva Centeno, Cavalheiro, Spetzler. Analysis and interpretation of data: Preul, Chaddad-Neto, Devanir Silva da Costa, Cavalheiro, Yağmurlu. Drafting the article: Preul, Chaddad-Neto, Devanir Silva da Costa, Yağmurlu. Critically revising the article: Preul, Chaddad-Neto, Yağmurlu, Spetzler. Reviewed submitted version of manuscript: Preul, Bozkurt, Grande. Statistical analysis: Devanir Silva da Costa. Administrative/technical/material support: Preul, Chaddad-Neto, Devanir Silva da Costa, Bozkurt, Grande, Yağmurlu. Study supervision: Preul, Spetzler.

\section{Correspondence}

Mark C. Preul, c/o Neuroscience Publications, Barrow Neurological Institute, St. Joseph's Hospital and Medical Center, 350 W Thomas Rd., Phoenix, AZ 85013. email: neuropub@ barrowneuro.org. 